\title{
Gastric cancer stem cells: therapeutic targets
}

\author{
Slavica Stojnev • Miljan Krstic • \\ Ana Ristic-Petrovic • Vladisav Stefanovic • \\ Takanori Hattori
}

Received: 1 October 2012/Accepted: 15 March 2013/Published online: 6 April 2013

(c) The International Gastric Cancer Association and The Japanese Gastric Cancer Association 2013

\begin{abstract}
During the past decade, a growing body of evidence has implied that cancer stem cells (CSCs) play an important role in the development of gastric cancer (GC). The notion that CSCs give rise to GC and may be responsible for invasion, metastasis, and resistance to treatment has profound implications for anti-cancer therapy. Recent major advances in the rapidly evolving field of CSCs have opened novel exciting opportunities for developing CSC-targeted therapies. Discovery of specific markers and signaling pathways in gastric CSCs (GCSCs), with the perfecting of technologies for identification, isolation, and validation of CSCs, may provide the basis for a revolutionary cancer treatment approach based on the eradication of GCSCs. Emerging therapeutic tools based on specific properties and functions of CSCs, including activation of self-renewal signaling pathways, differences in gene expression profiles, and increased activity of telomerase or chemoresistance mechanisms, are developing in parallel with advances in nanotechnology and bioengineering. The addition of GCSC-targeted therapies to current oncological protocols and their complementary application may be the key to successfully fighting GC.
\end{abstract}

S. Stojnev $(\bowtie) \cdot$ M. Krstic · A. Ristic-Petrovic

Faculty of Medicine, Institute of Pathology, University of Nis,

Zorana Djindjica Blvd 81, 18000 Nis, Serbia

e-mail: slavicastojnev@gmail.com;

slavica.stojnev@medfak.ni.ac.rs

V. Stefanovic

Department of Clinical Research, Faculty of Medicine,

University of Nis, 18000 Nis, Serbia

T. Hattori

Department of Pathology, Shiga University of Medical Science,

Seta Tsukinowa-cho, Otsu, Shiga 520-2121, Japan
Keywords Gastric cancer - Cancer stem cells - Targeted therapy · Cancer biomarkers · Epithelial-mesenchymal transition

\section{Gastric carcinogenesis and the cancer stem cell (CSC) hypothesis}

Immense progress has been made in unraveling the intricate carcinogenesis and molecular heterogeneity of stomach carcinoma, but there has been little improvement in clinical outcome of the disease. Despite the declining incidence, gastric cancer (GC) remains a worldwide health problem with significant mortality that has not decreased $[1,2]$. An obvious lack of efficient therapies emphasizes the need for the development of novel treatment modalities.

Genetic factors, Helicobacter pylori infection, dietary constituents, increased salt intake, carcinogens or their precursors such as nitrates in food, and smoking have all been implicated in the carcinogenesis of GC [3-7]. The introduction and evolution of the cancer stem cell (CSC) hypothesis have profoundly affected our perspective with regard to neoplastic disease. Compelling evidence indicates that cancer arises only from a small subpopulation of cells that possess the ability of self-renewal and indefinite proliferation which drives tumorigenesis [8-11]. CSCs retain the capacity to give rise to a hierarchy of phenotypically diverse progeny [12]. In addition to their undifferentiated nature, CSCs are endowed with relative resistance to apoptosis and the propensity to spread early. The CSC hypothesis suggests that cells capable of initiating and promoting tumor growth and metastasis are rare. However, recent studies have shown that under more permissive, modified xenotransplantation assay conditions, the 
detectable frequency of tumorigenic cells dramatically increases [13, 14].

To date, there is neither definition of CSCs in solid tumors nor a defined cluster of specific markers that specifically target cells meeting the criteria for CSCs in a certain type of tumor [15]. Although we cannot exclude the possibility of fully differentiated cells undergoing malignant transformation, experimental evidence supports the stem cell origin of most cancers. CSCs have been identified in breast, colorectal, and pancreatic cancer [10, 16, 17]. Recent evidence suggests that a small population of Lgr5+ cells found in the stomach and small intestine of mice is capable of forming long-lived organoids in culture [18]. Deletion of the $A P C$ gene in these scarce but rapidly cycling cells results in constitutive activation of the Wnt pathway and leads to the rapid and progressive development of adenomas [18, 19].

\section{Gastric cancer stem cells and their origin}

Gastric carcinoma has been suggested to contain and be driven by a subset of cells that display stem cell properties. Based on this progressive comprehension, putative gastric cancer stem cells (GCSCs) could generate multiple different types of cells within a carcinoma and fuel tumor growth and heterogeneity [20,21].

The origin of GCSCs has not yet been conclusively elucidated. GCSCs, tumor-initiating cells in the stomach, may be organ specific and arise from malignant transformation of normal stem cells (SCs) residing in stomach glands or from more differentiated progenitor cells that suffer oncogenic mutations and subsequently reactivate stemness-related properties. Because of their long lifespan and infinite proliferation, SCs are susceptible to mutations and epigenetic influences that alter their predetermined fate, converting them into a source for malignant clones $[12,15,22]$. Using mitochondrial DNA (mtDNA) mutations as a marker of clonal expansion, McDonald and coworkers provided evidence that human gastric body units were clonal and contained multiple SCs, where each unit and associated differentiated progeny contained an identical, mutated mtDNA genotype. They demonstrated the expansion of mutations within both normal mucosa and gastric mucosa showing intestinal metaplasia, thus providing a model of field cancerization in the human stomach [23].

Gastric adenocarcinoma may also originate from another recently proposed candidate, bone marrow-derived cells (BMDCs) [6, 20, 24]. Adult BMDCs have been considered to show a fair amount of plasticity, and they are considered capable of giving rise to not only blood elements and marrow stroma but also many different cell lineages when summoned to a site of chronic inflammation or injury [24, 25]. Houghton and coworkers demonstrated that BMDCs recruited by chronic Helicobacter infection and engrafted in gastric mucosa may subsequently undergo neoplastic transformation through a metaplasia/dysplasia/ carcinoma sequence. They showed that severe chronic inflammation in a C57BL/6 mouse model induced migration of BMDCs and repopulation of gastric glands. BMDCs later transformed into GC lineages. The study confirmed that most metaplasia, dysplasia, and cancer were donor derived [24]. Although further findings suggested that BMDCs might be the source of different tumor types [26], no subsequent study confirmed that BMDCs are capable of initiating gastric cancer. A recent study has proposed that CSC may ensue from the fusion of a local or bone marrowderived adult SC with a differentiated cell, if the accumulated genetic aberrations are sufficient for proliferative fusion [27, 28]. It was found that chronic inflammation, which represents a major risk factor for GC, vigorously promotes fusion of BMDCs with resident SCs [29, 30].

The possibility of a dynamic equilibrium between CSCs and non-CSCs within a tumor is based on the plasticity fueled by intensive crosstalk between numerous molecular pathways responsible for SC properties and epithelialmesenchymal transition (EMT). It has been suggested that CSCs can shift into non-CSCs under the influence of microenvironmental signals and through epigenetic modulations that are reversible and prompt in action [31]. Recently, it has been proposed that CSCs do not represent a definable subpopulation of cells but a highly dynamic state in which only a small number of cells are present at an observed moment of time, and where the results of cellsorting assays for SC properties may only represent a snapshot of the current cell conditions [15]. Current experimental protocols do not offer the possibility to elucidate whether CSCs represent a permanent or shifting functional state.

\section{Epithelial-mesenchymal transition (EMT) can generate GCSCs}

EMT, a multistep process by which epithelial cells acquire a fibroblastoid phenotype through loss of intercellular contacts and cytoskeleton reorganization, is based on molecular alterations in pathways closely associated with the maintenance of SC properties [32-34]. EMT is considered to be a crucial step in the dissemination of cancer because it contributes to its progression through cell invasion and metastasis $[33,35,36]$. Stationary CSCs that sustain tumor growth may also give rise to a special type of cells that are able to undergo transient EMT and acquire a migratory phenotype in addition to stemness [37]. The concept of "migrating CSCs" contributes to the explanation why metastases often recapitulate the evolution of 
primary tumors [37]. Recent findings strongly suggested that EMT is tightly intricate with acquisition of the CSC phenotype and notorious hallmarks of cancer, including invasiveness, distant dissemination, chemoresistance and radioresistance, and occurrence of minimal residual disease after therapy $[38,39]$.

A recent study has indicated that the propensity of GC cells to metastasize is associated with mesenchymal transition phenotype, decreased E-cadherin, and increased vimentin and matrix metalloproteinase 2 expression [40]. Moreover, a study that included 276 clinical specimens of primary GC suggested that the expression of EMT-related proteins was associated with CSC-like properties. A phenotype marked by positivity to Snail-1, vimentin, CD44, and loss of E-cadherin expression correlated with aggressive clinical features of $\mathrm{GC}$ and predicted disease-free survival. Interestingly, the expression of mesenchymal markers in lymph node metastasis was repressed and epithelial phenotype restored [41]. This finding is consistent with mesenchymal-epithelial transition, which is suggested to anchor circulating CSCs to the metastatic site, although the role of this process in metastatic dissemination is still a matter of debate [35].

\section{Identification and characterization of GCSCs}

The crucial step necessary to develop new therapeutic strategies focused on tumor-initiating cells in GC is the molecular characterization of GCSCs [42]. Within the past few years, exciting improvements in experimental techniques have allowed the isolation of tumor cell populations expressing specific surface markers. Current approaches to validate putative CSCs include the detection of SC markers, efflux analysis of DNA-binding Hoechst dye, and xenotransplantation assays that remain the gold standard to assess the potential of CSCs for self-renewal and tumorigenicity [8, $15,33]$. In addition, cells can be tested for their in vitro clonogenicity using a sphere-forming assay in a nonadherent culture, a serum-free medium containing epidermal growth factor and fibroblast growth factor 2 [43].

Significant difficulties in identification and isolation of GCSCs arise from the paucity of putative specific markers for GCSCs. Up to the present, the specificity of practically every explored marker has remained uncertain because accumulating evidence offers heterogeneous results, with even somewhat controversial findings resulting from very similar study designs, materials, and methods [21, 42-49] (Fig. 1).

\section{Tumor-initiating potential of side population cells in gastric cancer}

The so-called side population (SP), identified and isolated by the ability to efflux Hoechst 33342 dye, has been proposed as a potential source of SCs or even CSCs [5052]. It was found that SP cells isolated from human gastrointestinal tract cancer cell lines show overexpression of ATP-binding cassette (ABC) transporters associated with chemoresistance and overexpression of epithelial and mesenchymal markers linked with stemness [53]. However, the isolation of SP cells does not automatically enrich for CSCs, because SP-negative cells show an equal capacity to induce tumors in immunocompromised mice when compared with SP-enriched cells [21, 54].

Nevertheless, recent findings have provided new convincing evidence that GCSCs reside within the SP fraction, as indicated by overexpression of drug efflux proteins, enhanced chemoresistance, and proof of tumorigenicity in xeno-transplantation experiments [55-57]. The detection of differences in the expression of markers between SP and non-SP cells could provide a clue toward the identification of important CSC markers, which may act as therapeutic targets.

\section{Resistance of CSCs to cancer therapy}

Conventional oncological treatments target bulk tumor cells, but are not as effective on undifferentiated CSCs $[12,15]$. This minor fraction of cancer cell population evades chemotherapeutic action and regenerates heterogeneous cancer lineages [58, 59]. The resistance of CSCs to currently available therapies may be explained by numerous mechanisms, including the quiescence of CSCs and the location of some CSCs within hypoxic niches [33, 58-60]. A fraction of CSCs that remain quiescent is not susceptible to therapy that relies on cell-cycle arrest, thus affecting proliferation [61]. HIF1 $\alpha$ induced in a hypoxic environment inherent with cancer can decrease the proliferation rate of CSCs via c-Myc inhibition [62].

Stemness-related characteristics also involve multidrug resistance as a result of high expression of $\mathrm{ABC}$ transporters that effectively pump drugs out of the cell and overexpression of antiapoptotic proteins, including Bcl-2, Bcl-X, Flip, and inhibitor of apoptosis family members such as Survivin [33, 61, 63]. Moreover, resistance to specific therapy may result in enrichment of CSCs during antineoplastic treatments, as seen with cyclophosphamide treatment of colorectal cancer [64], which renders CSCs better equipped to evade death caused by cell damage. Tumor-initiating cells may also have enhanced DNA-repair mechanisms [63, 65].

Because CSCs are considered the main culprits responsible for the failure of contemporary anticancer therapy, there is a great, obvious, and critical need to develop efficient CSC-targeted treatment approaches. 
Fig. 1 Identification and characterization of gastric cancer stem cells (GCSCs). Validation of putative GCSCs includes detection of stem cell markers, efflux analysis of DNA-binding Hoechst dye, and testing of in vitro clonogenicity using a sphere-forming assay in nonadherent culture and xenotransplantation experiments that remain the gold standard to assess GCSC potential for self-renewal and tumorigenicity



\section{Cancer stem cell-targeted therapies}

Conventional therapies offer only limited success in stomach carcinoma treatment. Despite significant pharmacological progress and the recent introduction of novel therapeutic modalities, prognosis for patients with advanced-stage disease remains poor [1, 2, 66]. In addition, lack of selectivity may cause severe damage to normal tissues and further deteriorate quality of life. A notion that solid cancers arise from CSCs has had fundamental and profound implications for anticancer therapy. Targeted elimination of GCSCs that give rise to cancer cells and sustain tumor growth is proposed as one of the most promising paths in fighting malignant disease $[31,33,44$, 58].

Estimation of drug efficacy in current models is largely based on diminishing the tumor size. However, dramatic shrinkage and ablation of the majority of cancer cells does not reflect long-term treatment benefits. Tumor-initiating cells remain unaffected by cytostatic or cytotoxic agents and give rise to relapse after a period of apparent remission. A new progressive pharmacological approach is mandatory to efficiently target CSCs to prevent relapse or metastasis. However, methodological difficulties fetter the development of CSC-targeted therapies. First of all, there is a lack of relevant assays to identify and isolate CSC subtypes from cancer bulk cells. Cancer cell lines represent the major tool in the extremely demanding process from target recognition to effectiveness assessment of discovered drugs in preclinical settings. However, the predictive value of drug efficacy based on in vitro observations is quite poor and cannot be translated in an acceptable manner into clinical settings [31, 67].

Basically, there are two main approaches in the attempt to eradicate CSCs: their elimination or their induced differentiation $[68,69]$. The aim of differentiation therapy is for CSCs to lose their self-renewal capacity, which would make tumor growth unsustainable. This loss may be achieved by agents that affect cancer cell differentiation, such as retinoic acid and drugs causing epigenetic modifications. Application of all-trans retinoic acid (ATRA)based induction therapy followed by chemotherapy has made acute promyelocytic leukemia a curable disease [70]. In vitro, retinoic acid effectively induces differentiation in embryonic cells, teratocarcinomas, and melanomas; however, retinoid treatment of solid tumors such as prostate or liver cancer has yielded limited results [68]. Recent findings suggest that ATRA can reduce sphere-forming capacity in breast cancer cell lines [71]. In addition, treatment with bone morphogenetic proteins reportedly 


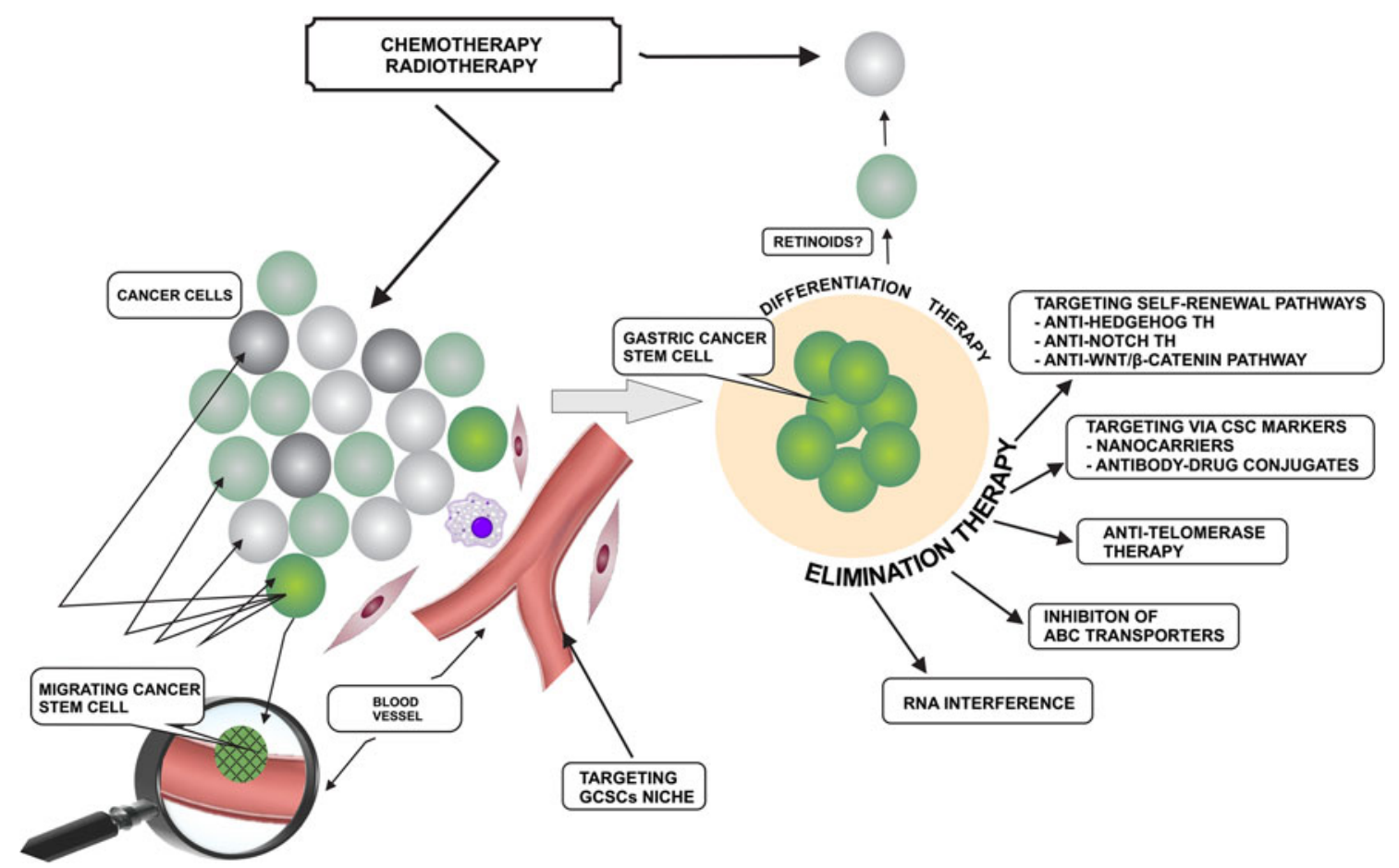

Fig. 2 Possible approaches for targeting gastric cancer stem cells (GCSCs). GCSCs may be responsible for the failure of conventional therapeutic modalities for gastric carcinoma. They possess a selfrenewal capacity and the ability to give rise to multiple heterogeneous cancer cell lineages and are considered to be the culprit for metastasis and cancer relapse after treatment. Addition of GCSC-targeted therapies to current oncological protocols and their complementary application may bring significant clinical benefits. The aim of

decreased the CD133+ population of putative glioblastoma SCs by forcing them to differentiate into astrocytes [72].

Elimination therapy is aimed at targeted extermination of the SC pool of cancer cells. Various therapeutic strategies may be used to achieve this goal and concurrently avoid nonspecific toxicity and deleterious side effects of conventional therapy. Most of these developing approaches are based on specific properties of CSCs, including activation of self-renewal and stemness-maintaining signaling pathways, differences in gene expression profiles, and increased activity of telomerase or chemoresistance mechanisms (Fig. 2).

GCSCs targeting based on drug carriers tailored for CSC markers

These therapies are based on differential expression of specific surface markers in tumor cell subpopulations that are enriched for CSCs. The era of high-throughput techniques and personalized medicine has accelerated the discovery of fresh and promising therapeutic platforms [73]. Emerging anticancer strategies are based on the development of nanocarriers that can bind multiple drugs and differentiation therapy is for GCSCs to lose their self-renewal capacity, making tumor growth unsustainable. Elimination therapy is directed at targeted extermination of GCSCs and is based on the specific functions and properties of GCSCs, including activation of self-renewal and stemness-maintaining signaling pathways, differences in gene expression profiles, and increased activity of telomerase or chemoresistance mechanisms

molecules, which can selectively and efficiently target cancer cells, especially CSCs.

Aptamers, the nonimmunogenic and nontoxic small oligonucleic acid molecules that can specifically bind to a desired site and penetrate cancer cells, are expected to help in overcoming the disadvantages of conventional chemotherapy [74, 75]. The first RNA aptamer against a CSC surface marker has recently been identified. Shigdar and coworkers [75] have isolated an aptamer against epithelial cell adhesion molecule (EpCAM), a putative marker of CSCs. The synthesized ligand specifically interacts with EpCAM-expressing cancer cells derived from human gastric, colorectal, and breast cancer and is actively internalized upon this interaction.

Targeted delivery of cytotoxic agents potent in the picomolar range using monoclonal antibodies is a promising concept currently undergoing preclinical development or clinical evaluation for treatment of many forms of cancer. Antibody-drug conjugates (ADCs) exert great specificity and may be considered tumor-activated prodrugs because the toxicity is triggered only within the tumor cells upon binding of ADCs to corresponding antigens, followed by internalization and lysosomal processing 
and cleavage of drug-antibody linkers [76, 77]. Conjugation of calicheamicin to hu3s193 antibody directed against Lewis y antigen (CD174), which is overexpressed on gastric carcinomas [78] as well as carcinomas of the colon, breast, lung, prostate, and ovary, demonstrated antitumor activity in vivo and caused growth arrest of xenografted gastric carcinomas for at least 100 days [79]. The first clinical trials of humanized antibody hu3s193 in patients with advanced epithelial cancer confirmed high selectivity in tumor targeting and favorable pharmacokinetics [80]. Targeting tumor cells positive for putative CSC-related markers with ADCs has the potential to eliminate CSCs as well as tumor cells without stem-like properties positive for a designated antigen. Smith and coworkers investigated the ability of ADCs to selectively target CD133+ cells bound to bear CSC properties, although the CD133 surface marker is not restricted to CSCs. A murine anti-human CD133 monoclonal antibody was conjugated to the highly cytotoxic drug monomethyl auristatin $\mathrm{F}$, which induced apoptosis in cancer cells with a high level of CD133 expression. This step led to inhibition of GC cell growth in both in vitro and in vivo conditions [45].

ADCs may be used in combination with chemotherapy or radiotherapy, which eliminates bulk tumor cells and leaves the targeted CSCs more accessible to ADCs [45, 76]. This strategy has already proven to be clinically beneficial in the treatment of acute myeloid leukemia, where the addition of gemtuzumab ozogamicin to cytotoxic chemotherapy improved disease-free and overall survival [81]. ADC- and nanocarrier-based approaches have already produced tangible benefits in cancer research and will certainly represent attractive tools in the treatment of GC and other solid neoplasms.

Targeting self-renewal pathways

Strategies targeting self-renewal pathways directed at elimination of CSCs are based on extensive similarities between normal SCs and CSCs: these include targeting of stemness-related signaling pathways such as Hedgehog (Hh), Notch/Delta, Wnt/ $\beta$-catenin, JAK/STAT, and transforming growth factor (TGF)- $\beta$, which have been widely implicated in CSC maintenance [15, 58, 82].

It is well known that inflammation caused by Helicobacter pylori infection and consecutive elevation of proinflammatory cytokines such as interferon (INF)-gamma, tumor necrosis factor (TNF)- $\alpha$, and interleukin (IL)-1 $\beta$ play a pivotal role in the development of GC [83]. Chronic stimulation in response to various harmful stimuli and subsequent repair and regeneration processes activate tissue progenitor cells through developmental signaling pathways. Deregulation in homeostatic mechanisms that govern tissue repair and SC self-renewal may lead to cancerous growth [84]. Inhibitors of signaling pathways most likely employed in maintenance of the self-renewal capacity and perpetual proliferation of CSCs have emerged as an important new class of therapeutic agents.

\section{Hedgehog pathway}

Hh molecules (Sonic, Indian, and Desert Hedgehog) are important signaling proteins that play critical roles in the development and differentiation of many tissues and maintenance of adult SCs and CSCs [85, 86]. Hh signaling is involved in the differentiation of gastric progenitor cells into mucous cells and parietal cells during the gastric ulcer repair process [85]. A loss of gastric tissue homeostasis resulting in Correa sequence is associated with the impairment of Sonic Hedgehog (Shh) within the acidsecreting glands in atrophic gastritis and intestinal metaplasia $[87,88]$. The loss of parietal cells and a higher luminal $\mathrm{pH}$ associated with $H$. pylori chronic infection decreases Shh signaling, essential for restitution of damaged gastric mucosa from SCs [88, 89]. However, loss of Shh alone is not sufficient to cause parietal cell atrophy and trigger GC [90]. In fact, GC is associated with increased Shh signaling [88, 91]. Lee and coworkers [92] have recently demonstrated in vitro that late reactivation of Shh by $H$. pylori infection selects the gastric epithelial cells resistant to apoptosis, which is associated with carcinogenesis in settings of atrophic gastritis and deregulated proliferation.

Reappearance of Shh during gastric carcinogenesis needs to be further clarified. High levels of Shh found in GC may be caused by repopulation of the gastric mucosa by SCs, which possibly includes the recruitment of bone marrow-derived mesenchymal stem cells (BM-MSCs) as a part of the inflammatory response [24, 88]. BM-MSCs were found to possess the property of spontaneous transformation [93], whereas the Hh pathway was recognized as the key factor for growth and proliferation of these spontaneously transformed MSCs in vivo [94]. MSC-like cells have been isolated from both human GC and adjacent noncancerous tissue [95].

Several studies showed that cyclopamine treatment of GC cell lines inhibited cell growth, especially in cell lines that expressed high levels of SMO, an important downstream protein in the Hh pathway [2,96]. Cyclopamine, a specific inhibitor of $\mathrm{Hh}$ signaling, decreased the number of cells with the pit phenotype [96]. A recent study showed that cyclopamine significantly inhibited the differentiation of mucous cells and parietal cells during the gastric regeneration process; however, it did not affect their proliferation [85]. Further clues elucidating abnormal Shh signaling in the maintenance of GCSCs arose from a study by Song and coworkers, who isolated tumor sphere cells 
that showed an increased self-renewal capacity and chemoresistance, expressed CSC-related markers (CD44, CD24, and CD133), and had higher tumorigenic capacity in vivo. The expression of Shh pathway target genes (Ptch and Glil) was significantly higher in the isolated cells. Blocking the Shh pathway with cyclopamine decreased the self-renewing properties and enhanced sensitivity to chemotherapeutic agents [97].

Targeted inhibition of the Hh pathway carries great potential to prevent and treat GC as well as many other types of human cancers [98]. Optimal results are expected from the combined use of Hh inhibitors and cytotoxic drugs because stomach carcinoma is associated with complex deregulation of the Hh pathway, including constitutive activation of the Hh pathway and autocrine and paracrine Hh signaling [99]. Several $\mathrm{Hh}$ antagonists are undergoing clinical evaluation and have shown satisfactory efficacy and safety up date, particularly in the treatment of basal cell carcinoma and medulloblastoma, both of which are associated with constitutive activation of the Hh pathway. The first identified $\mathrm{Hh}$ pathway inhibitor, cyclopamine, has been upstaged by a new generation of small molecules that inactivate SMO and have higher potency and more favorable bioavailability and pharmacokinetic profile [98]. The synthetic Hh inhibitor GDC-0449 is available for oral use and is in the advanced phase of clinical evaluation for the management of several solid cancers [98]. Robotnikinin, a small molecule that binds extracellular Shh, has recently been shown to effectively inhibit Shh signaling in vitro [100]. Hh-blocking antibodies that prevent the binding of $\mathrm{Hh}$ to $\mathrm{PTCH}-$ like 5E1 are also available [99]. Some drug candidates that act downstream of SMO successfully blocked tumor growth in a xeno-transplantation model through inhibition of GLI-mediated transcription [101]. Although GC has been unequivocally linked to Hh overexpression, and Hh inhibitors have been proven successful in blocking tumor growth in preclinical settings, anti-Hh compounds have not yet been tested in human subjects suffering from GC. Nevertheless, favorable results from clinical studies of other cancers and rapid improvements in the pharmacological properties of novel $\mathrm{Hh}$ antagonists would have far-reaching effects on GC therapy.

\section{Notch pathway}

The Notch signaling pathway is suggested to have critical significance in SC self-renewal and is involved in cell fate determination of progenitors [102, 103]. Aberrant Notch signaling is found to be oncogenic in many types of human cancers, including lung, breast, and ovarian cancer as well as leukemia and others [104-106].

A study that investigated the expression of Notch-related genes (Notch1,2,3, Hes 1,2,3, Hathl) in eight GC cell lines suggested the role of the canonical Notch pathway in the carcinogenesis of GC. It was found that Hath1 is one of the transcriptional regulators for the gastric mucin genes MUC5AC and MUC6, which are markers of a chief cell lineage. That finding implied that possible loss of Hath1 expression may result in disruption of gastric cell differentiation and promotion of cancer development in the stomach [107]. A recent study has shown that Notch1 activity in GC is controlled by the epigenetic silencing of the Delta-like1 ligand [108]. In addition to GC cell lines, a recent study included surgical and endoscopic specimens of primary GC and recognized the link between Notch1 activation and intestinal phenotypes of gastric lesions. Notch2 correlated with nuclear labeling of Hes1, the product of the Notch target gene Hes. GC cell lines that expressed Notch2 and Hes1 did not express Notch1 [109].

Gamma-secretase inhibitors antagonize Notch signaling via blocking of Notch receptor cleavage. Their use in the treatment of cancers with impaired Notch signaling is being investigated as a promising therapeutic strategy [110]. Combination therapy with glucocorticoids offers new opportunities to overcome side effects, including severe gastrointestinal toxicity precipitated by gammasecretase inhibitors [111]. However, evaluation of the effects of two specific gamma-secretase antagonists in two GC cell lines resulted in neither growth arrest nor cell death, although Hes1 expression was decreased [109]. The multifaceted qualities of Notch molecules and great variations in their biological functions suggest the need to assess the status of Notch signaling in every different tumor type and even subtype [109]. Notch1 inhibition was found to be associated with diffuse-type stomach cancer [108, 109]. Therefore, application of Notch antagonists may theoretically be useless or have very limited effects. This finding emphasizes the importance of an accurate diagnosis of carcinoma subtype and precise molecular characterization to identify patients who can benefit from anti-Notch therapy [112]. Although inhibition of proteolytic activation of Notch signaling has so far failed to evince significant anticancer effects in GC, the data are quite scant and further studies are required.

Affecting the pathways involved in the maintenance of normal and CSC anticancer agents may cause irreversible damage to healthy tissue, raising the question of safety in application of stemness-targeted drugs. Recent findings have suggested that there may be a therapeutic window that allows the development of therapies to eliminate CSCs without damaging normal SCs [67, 113]. CSCs may employ the same pathways in sustaining self-renewal properties, but with totally different effects of their loss. Yilmaz and coworkers investigated the effect of deletion of Pten, regulated by Notch1, on leukemia-initiating cells and normal adult hematopoietic SCs in mice. They observed a mechanistic difference between CSCs and normal SCs, 
with Pten deletion leading to myeloproliferative disease and, on the other hand, causing depletion of hematopoietic $\mathrm{SCs}$, which were unable to maintain themselves in the absence of Pten. Rapamycin (sirolimus), a macrolide immunosuppressant drug, inhibits the mTOR pathway, which is activated in downstream Pten signaling. Administration of rapamycin to Pten-deleted mice resulted in restoration of hematopoietic SCs and depletion of leukemia-initiating cells [113]. In addition, Fan et al. observed selective vulnerability to drugs inhibiting the Notch pathway of stem-like cells in embryonal brain tumors. They found that Notch blockade inhibited tumor engraftment by a significant decrease in CD133+ cells and abrogation of SP cells [114].

\section{Wnt/ $\beta$-catenin pathway}

The Wnt signaling pathway has been recognized as pivotal in tissue repair and SC renewal within the niche. In carcinogenesis, the canonical Wnt pathway is implicated in maintenance and proliferation of CSCs and induction of EMT, thus linking the following two crucial points of cancer progression: the very existence of CSCs and acquisition of the mesenchymal phenotype required for dissemination [84, 115]. Wnt aberrant activation was also linked to the development of gastric adenocarcinoma. Mutations in the $\beta$-catenin gene are common in GCs showing nuclear $\beta$-catenin expression [116]. Chronic persistent inflammation and associated tissue regeneration, as seen in H. pylori infection of the stomach, evoke transcriptional activation of the canonical Wnt network [117]. Transduction of canonical Wnt signals is exerted through Frizzled family receptors and LRP5 and LRP6 coreceptors downstream to the $\beta$-catenin signaling cascade [118]. Recently, Cai and Zhu [119] suggested that the Wnt/ $\beta$ catenin pathway bears essential significance for the selfrenewal of cancer stem-like cells in human GC.

Small molecules that target $\beta$-catenin-dependent Wnt signaling cascade as well as anti-Wnt antibodies are awaiting translation into clinical practice [117, 119]. Salinomycin, an antibiotic widely used in poultry farming, was identified as a potent inhibitor of CSCs [120]. The potency of salinomycin is based on the suppression of Wnt/ $\beta$-catenin signal transduction. Salinomycin selectively abolished CSCs in breast cancer and induced apoptosis in chronic lymphocytic leukemia cells with an aberrant Wnt signaling cascade $[115,120]$. In GC, salinomycin has been reported to be highly effective against the CSC fraction of the tumor population. Zhi and colleagues observed that ALDH-high cells displayed CSC properties, including high expression of Sox2, Nanog, and Nestin, increased colony formation, and higher chemoresistance compared with ALDH-low cancer cells. These putative GCSCs showed significantly higher sensitivity to salinomycin in vitro [121].

Anti-telomerase therapy

Shortening of telomeres triggers replicative senescence or apoptosis [122]. Tumor cells overcome this limitation by reactivation of telomerase, RNA template-dependent DNA synthase, which provides them with a selective growth advantage [123, 124]. Increased telomerase activity underlies the potential of CSCs to proliferate indefinitely and sustain immortality. Several anti-telomerase agents are currently in clinical trials for treatment of solid neoplasms and are speculated to efficiently target CSCs [63, 123].

Tankyrase 1 has been recognized as one of the telomerespecific binding proteins that contribute to maintenance of telomerase length. Findings of a recent study have implied that concomitant inhibition of tankyrase 1 and telomerase has a synergistic effect on telomere length shortening in the SGC-7901 GC cell line. Coinhibition of telomerase activity and tankyrase 1 thus emerged as a rational anticancer therapeutic approach [125]. Treatment of human GC AGS lines with glycoprotein isolated from Laminaria japonica downregulated telomerase activity and human telomerase reverse transcriptase (hTERT) expression [126], which is high in GC [127]. In addition, this glycoprotein decreased prostaglandin $E_{2}$ synthesis and effectively induced apoptosis in cancer cells, which made it a candidate for further anticancer research [126].

\section{$\mathrm{ABC}$ transporters}

Overexpression of detoxifying enzymes and efflux pumps may allow cancer cells to evade the cytotoxic action of pharmaceuticals, thus worsening treatment outcomes [33, $61,128]$. Genes such as $A B C G 2$ and $A B C B 1 / M D R 1$ encoding for $\mathrm{ABC}$ transporters that efficiently eliminate various xenobiotics from normal SCs are also found to be expressed in many tumor cells that exhibit stem-like properties [51, 52]. If used in combination with chemotherapy, selective inhibition of $\mathrm{ABC}$ transporters could be beneficial, especially in eradication of multidrug-resistant cancer cells [67, 129, 130]. However, inhibition of ABC transporters is likely to have significant side effects, including toxic action on normal SCs. It also affects bloodbrain barrier maintenance, where these transmembrane proteins play an important role [128].

Regulating the CSC microenvironmental niche

SCs in normal gastric mucosa are thought to populate the proliferative zone in the neck-isthmus region [6, 131]. Crypts in the stomach may act as niches for SCs, where 
surrounding structures and arising interactions contribute to the maintenance of stem/progenitor cell proliferation and differentiation [23, 131]. It has been suggested that CSCs reside only in designated conditioned compartments with an adequate cancer cell-stroma interface [23, 132]. The specialized CSC niche may be provided by more differentiated cancer cells and stromal cells; therefore, CSCs may not be limited by topology of the tumor and can be found anywhere in the tumor mass [133]. Inability to reproduce the effects of the niche compartment is one of the most important obstacles in translating results from in vitro experiments to animal models [15, 132].

Regulating various components of the CSC microenvironment and niche, such as intracellular reactive oxygen species levels and tumor angiogenesis, has been suggested as a potential therapeutic approach $[134,135]$. When bulk cancer cells are diminished by chemotherapy, CSCs are left in awkward situations without necessary nourishment, which may be sufficient for their extinction [133]. In addition, BMDCs and MSC-like cells recently isolated from GC and adjacent noncancerous tissues [95, 136] may be the source of carcinoma-associated fibroblasts, which are suspected to promote tumor cell growth, and, along with MSCs, contribute to the CSC niche [137]. An in-depth understanding of in vitro/in vivo crosstalk between different cell types within the tumor milieu may give rise to improved anticancer strategies [137, 138].

Small molecule therapeutics, gene therapy

CSC-targeted therapy based on the application of microRNA is gaining increased attention [33]. MicroRNAs, small noncoding RNA molecules, and RNA interference bear the potential to modify gene expression and control important cellular mechanisms, including EMT, apoptosis, and cell proliferation [139]. Recent studies demonstrated that some miRNAs are differentially expressed in GC tissues, and that miRNAs may exert oncogenic, tumor suppressor, or controversial roles in GC [140]. Silencing of Snail, a potent repressor of the E-cadherin gene and prominent member of the Wnt network, by stable RNA interference induced mesenchymal-epithelial transition that resulted in a dramatic decrease of tumor growth in vivo [141].

Using genetically engineered SCs with tumor-selective migration capabilities and expressing suicide genes may have tremendous therapeutic potential for cancer treatment, with dramatically improved selectivity [142]. Recently, genetically engineered SCs with fused gene expression of cytosine deaminase (CD) and interferon- $\beta$ have been designed. Cytosine deaminase metabolizes a nontoxic 5-fluorocytosine into the cytotoxic agent 5-fluorouracil, whereas interferon- $\beta$ has anticancer effects. These cells have been shown to migrate toward AGS GC cells and significantly inhibit their growth because of the synergistic effect of CD and INF- $\beta$ genes in the presence of 5-fluorouracil [143].

\section{Current limitations and future perspectives}

The research field of GCSCs has been recently marked by significant achievements. Despite certain breakthroughs, the road of unraveling the mystery of GCSCs is yet to be traveled. Rapidly mounting evidence suggests that CSCs not only sustain tumor growth but also cause relapse after therapy. However, a reliable set of GCSC markers has not yet been established, which impedes identification and isolation of these cells. CSCs may show significant heterogeneity and contain phenotypically different fractions even in a single cancer type. Being in constant communication with their niche and surrounding cells, CSCs represent a very dynamic system that further complicates CSC-targeted therapy. There is a need to gain a more complete understanding of the pathways and molecules that regulate the SC state. Nevertheless, therapy targeting GCSCs may at least contribute to improving the outcome of GC patients.

Further research and rapid development of highthroughput technologies and bioinformatics will allow the use of molecular signatures of genetic and epigenetic alterations of CSC-associated molecules as biomarkers for GC. Drugs blocking signaling pathways required for CSC maintenance, such as Notch, Hh, or Wnt, will be used to deplete GCSCs, whereas simultaneous application of traditional anticancer drugs will allow the debulking of a larger tumor mass. This combined therapeutic regimen may target two putative populations of GC, GCSCs, and better differentiated cells, which will minimize the possibility of residual tumor-initiating cells. Finally, there is a need to emphasize the importance of accounting for nonneoplastic SCs in the development of these promising novel strategies and discovering valuable therapeutic windows that will allow employment of anti-CSC agents without deleterious effects on the normal and vital SCs.

Novel insights in gastric carcinogenesis and a deeper understanding of the molecular mechanisms and pathways that regulate GCSCs are paving the highway for extraordinary progress in the battle against stomach carcinoma. Tumor-initiating cells need to be targeted vigorously to eradicate malignant disease because they can often be particularly chemo- and radioresistant. Optimal results will be achieved with a combination of conventional and CSCtargeted therapy. A synergistic approach based on simultaneous targeting of different yet essential aspects of cancer's devastation force (CSC pool, neoangiogenesis, 
resistance to apoptosis) approximates the best available response to this horrible disease. The addition of GCSCtargeting therapeutic tools to current protocols and their complementary application may be the answer to successful GC treatment.

Acknowledgments This work was supported by Grant No. 175092, from the Ministry of Education and Science of Serbia. We thank Milan Rakic for excellent technical support. The authors declare no conflict of interest.

\section{References}

1. Jemal A, Bray F, Center MM, Ferlay J, Ward E, Forman D. Global cancer statistics. CA Cancer J Clin. 2011;61:69-90.

2. Milne AN, Carneiro F, O'Morain C, Offerhaus GJ. Nature meets nurture: molecular genetics of gastric cancer. Hum Genet. 2009;126:615-28.

3. Katoh M. Dysregulation of stem cell signaling network due to germline mutation, SNP, Helicobacter pylori infection, epigenetic change and genetic alteration in gastric cancer. Cancer Biol Ther. 2007;6:832-9.

4. Hagiwara T, Mukaisho K, Nakayama T, Sugihara H, Hattori T. Long-term proton pump inhibitor administration worsens atrophic corpus gastritis and promotes adenocarcinoma development in Mongolian gerbils infected with Helicobacter pylori. Gut. 2011;60:624-30.

5. Fox JG, Wang TC. Inflammation, atrophy, and gastric cancer. J Clin Invest. 2007;117:60-9.

6. Saikawa Y, Fukuda K, Takahashi T, Nakamura R, Takeuchi H, Kitagawa Y. Gastric carcinogenesis and the cancer stem cell hypothesis. Gastric Cancer. 2010;13:11-24.

7. Kakinoki R, Kushima R, Matsubara A, Saito Y, Okabe H, Fujiyama $\mathrm{Y}$, et al. Re-evaluation of histogenesis of gastric carcinomas: a comparative histopathological study between Helicobacter pylori-negative and $H$. pylori-positive cases. Dig Dis Sci. 2009;54:614-20.

8. Clarke MF, Dick JE, Dirks PB, Eaves CJ, Jamieson CH, Jones DL, et al. Cancer stem cells-perspectives on current status and future directions: AACR workshop on cancer stem cells. Cancer Res. 2006;66:9339-44.

9. Al-Hajj M, Clarke MF. Self-renewal and solid tumor stem cells. Oncogene. 2004;23:7274-82.

10. Al-Hajj M, Wicha MS, Benito-Hernandez A, Morrison SJ, Clarke MF. Prospective identification of tumorigenic breast cancer cells. Proc Natl Acad Sci USA. 2003;100:3983-8.

11. Kelly PN, Dakic A, Adams JM, Nutt SL, Strasser A. Tumor growth need not be driven by rare cancer stem cells. Science. 2007;317:337.

12. Reya T, Morrison SJ, Clarke MF, Weissman IL. Stem cells, cancer, and cancer stem cells. Nature (Lond). 2001;414:105-11.

13. Quintana E, Shackleton M, Sabel MS, Fullen DR, Johnson TM, Morrison SJ. Efficient tumour formation by single human melanoma cells. Nature (Lond). 2008;456:593-8.

14. Quintana E, Shackleton M, Foster HR, Fullen DR, Sabel MS, Johnson TM, et al. Phenotypic heterogeneity among tumorigenic melanoma cells from patients that is reversible and not hierarchically organized. Cancer Cell. 2010;18:510-23.

15. Welte Y, Adjaye J, Lehrach HR, Regenbrecht CR. Cancer stem cells in solid tumors: elusive or illusive? Cell Commun Signal. 2010;8:6.

16. O'Brien CA, Pollett A, Gallinger S, Dick JE. A human colon cancer cell capable of initiating tumour growth in immunodeficient mice. Nature (Lond). 2007;445:106-10.
17. Li C, Heidt DG, Dalerba P, Burant CF, Zhang L, Adsay V, et al. Identification of pancreatic cancer stem cells. Cancer Res. 2007;67:1030-7.

18. Barker N, Clevers H. Leucine-rich repeat-containing G-protein coupled receptors as markers of adult stem cells. Gastroenterology. 2010;138:1681-96.

19. Barker N, Ridgway RA, van Es JH, van de Wetering M, Begthel $\mathrm{H}$, van den Born $\mathrm{M}$, et al. Crypt stem cells as the cells-of-origin of intestinal cancer. Nature (Lond). 2009;457:608-11.

20. Takaishi S, Okumura T, Wang TC. Gastric cancer stem cells. J Clin Oncol. 2008;26:2876-82.

21. Takaishi S, Okumura T, Tu S, Wang SS, Shibata W, Vigneshwaran $\mathrm{R}$, et al. Identification of gastric cancer stem cells using the cell surface marker CD44. Stem Cells. 2009;27: 1006-20.

22. Regenbrecht CR, Lehrach H, Adjaye J. Stemming cancer: functional genomics of cancer stem cells in solid tumors. Stem Cell Rev. 2008;4:319-28.

23. McDonald SA, Greaves LC, Gutierrez-Gonzalez L, RodriguezJusto M, Deheragoda M, Leedham SJ, et al. Mechanisms of field cancerization in the human stomach: the expansion and spread of mutated gastric stem cells. Gastroenterology. 2008;134:500-10.

24. Houghton J, Stoicov C, Nomura S, Rogers AB, Carlson J, Li H, et al. Gastric cancer originating from bone marrow-derived cells. Science. 2004;306:1568-71.

25. Jiang Y, Jahagirdar BN, Reinhardt RL, Schwartz RE, Keene $\mathrm{CD}$, Ortiz-Gonzalez XR, et al. Pluripotency of mesenchymal stem cells derived from adult marrow. Nature (Lond). 2002;418:41-9.

26. Liu C, Chen Z, Chen Z, Zhang T, Lu Y. Multiple tumor types may originate from bone marrow-derived cells. Neoplasia. 2006;8:716-24.

27. Lu X, Kang Y. Cell fusion as a hidden force in tumor progression. Cancer Res. 2009;69:8536-9.

28. Bjerkvig R, Tysnes BB, Aboody KS, Najbauer J, Terzis AJ. Opinion: The origin of the cancer stem cell: current controversies and new insights. Nat Rev Cancer. 2005;5:899-904.

29. Johansson CB, Youssef S, Koleckar K, Holbrook C, Doyonnas $\mathrm{R}$, Corbel SY, et al. Extensive fusion of haematopoietic cells with Purkinje neurons in response to chronic inflammation. Nat Cell Biol. 2008;10:575-83.

30. Nygren JM, Liuba K, Breitbach M, Stott S, Thorén L, Roell W, et al. Myeloid and lymphoid contribution to non-haematopoietic lineages through irradiation-induced heterotypic cell fusion. Nat Cell Biol. 2008;10:584-92.

31. Gupta PB, Chaffer CL, Weinberg RA. Cancer stem cells: mirage or reality? Nat Med. 2009;15:1010-2.

32. Hayashida T, Jinno H, Kitagawa Y, Kitajima M. Cooperation of cancer stem cell properties and epithelial-mesenchymal transition in the establishment of breast cancer metastasis. J Oncol. 2011;2011:591427.

33. Alison MR, Lim SM, Nicholson LJ. Cancer stem cells: problems for therapy? J Pathol. 2011;223:147-61.

34. Fuxe J, Vincent T, Garcia de Herreros A. Transcriptional crosstalk between TGF- $\beta$ and stem cell pathways in tumor cell invasion: role of EMT promoting Smad complexes. Cell Cycle. 2010;9:2363-74.

35. Brabletz T. To differentiate or not-routes towards metastasis. Nat Rev Cancer. 2012;12:425-36.

36. Iwatsuki M, Mimori K, Yokobori T, Ishi H, Beppu T, Nakamori $\mathrm{S}$, et al. Epithelial-mesenchymal transition in cancer development and its clinical significance. Cancer Sci. 2010;101:293-9.

37. Brabletz T, Jung A, Spaderna S, Hlubek F, Kirchner T. Opinion: migrating cancer stem cells - an integrated concept of malignant tumour progression. Nat Rev Cancer. 2005;5:744-9. 
38. Mani SA, Guo W, Liao MJ, Eaton EN, Ayyanan A, Zhou AY, et al. The epithelial-mesenchymal transition generates cells with properties of stem cells. Cell. 2008;133:704-15.

39. Kurrey NK, Jalgaonkar SP, Joglekar AV, Ghanate AD, Chaskar PD, Doiphode RY, et al. Snail and slug mediate radioresistance and chemoresistance by antagonizing p53-mediated apoptosis and acquiring a stem-like phenotype in ovarian cancer cells. Stem Cells. 2009;27:2059-68.

40. Yang L, Ping YF, Yu X, Qian F, Guo ZJ, Qian C, et al. Gastric cancer stem-like cells possess higher capability of invasion and metastasis in association with a mesenchymal transition phenotype. Cancer Lett. 2011;310:46-52.

41. Ryu HS, Park DJ, Kim HH, Kim WH, Lee HS. Combination of epithelial-mesenchymal transition and cancer stem cell-like phenotypes has independent prognostic value in gastric cancer. Hum Pathol. 2012;43:520-8.

42. Chen T, Yang K, Yu J, Meng W, Yuan D, Bi F, et al. Identification and expansion of cancer stem cells in tumor tissues and peripheral blood derived from gastric adenocarcinoma patients. Cell Res. 2012;22:248-58.

43. Han ME, Jeon TY, Hwang SH, Lee YS, Kim HJ, Shim HE, et al. Cancer spheres from gastric cancer patients provide an ideal model system for cancer stem cell research. Cell Mol Life Sci. 2011;68:3589-605.

44. Dhingra S, Feng W, Brown RE, Zhou Z, Khoury T, Zhang R, et al. Clinicopathologic significance of putative stem cell markers, CD44 and nestin, in gastric adenocarcinoma. Int J Clin Exp Pathol. 2011;4:733-41.

45. Smith LM, Nesterova A, Ryan MC, Duniho S, Jonas M, Anderson M, et al. CD133/prominin-1 is a potential therapeutic target for antibody-drug conjugates in hepatocellular and gastric cancers. Br J Cancer. 2008;99:100-9.

46. Wang T, Ong CW, Shi J, Srivastava S, Yan B, Cheng CL, et al. Sequential expression of putative stem cell markers in gastric carcinogenesis. Br J Cancer. 2011;105:658-65.

47. Jiang J, Zhang Y, Chuai S, Wang Z, Zheng D, Xu F, et al. Trastuzumab (herceptin) targets gastric cancer stem cells characterized by CD90 phenotype. Oncogene. 2012;31:671-82.

48. Zhang C, Li C, He F, Cai Y, Yang H. Identification of CD44+CD24+ gastric cancer stem cells. J Cancer Res Clin Oncol. 2011;137:1679-86.

49. Xue Z, Yan H, Li J, Liang S, Cai X, Chen X, et al. Identification of cancer stem cells in vincristine preconditioned SGC7901 gastric cancer cell line. J Cell Biochem. 2012;113:302-12.

50. Hadnagy A, Gaboury L, Beaulieu R, Balicki D. SP analysis may be used to identify cancer stem cell populations. Exp Cell Res. 2006;312:3701-10.

51. Scharenberg CW, Harkey MA, Torok-Storb B. The ABCG2 transporter is an efficient Hoechst 33342 efflux pump and is preferentially expressed by immature human hematopoietic progenitors. Blood. 2002;99:507-12.

52. Zhou S, Schuetz JD, Bunting KD, Colapietro AM, Sampath J, Morris JJ, et al. The $\mathrm{ABC}$ transporter Bcrp1/ABCG2 is expressed in a wide variety of stem cells and is a molecular determinant of the side-population phenotype. Nat Med. 2001;7:1028-34.

53. Haraguchi N, Utsunomiya T, Inoue H, Tanaka F, Mimori K, Barnard GF, et al. Characterization of a side population of cancer cells from human gastrointestinal system. Stem Cells. 2006;24:506-13.

54. Alison MR, Poulsom R, Brittan M, Schier S, Burkert J, Wright NA. Isolation of gut SP cells does not automatically enrich for stem cells. Gastroenterology. 2006;130:1012-4.

55. Fukuda K, Saikawa Y, Ohashi M, Kumagai K, Kitajima M, Okano $\mathrm{H}$, et al. Tumor initiating potential of side population cells in human gastric cancer. Int J Oncol. 2009;34:1201-7.
56. Schmuck R, Warneke V, Behrens HM, Simon E, Weichert W, Röcken C. Genotypic and phenotypic characterization of side population of gastric cancer cell lines. Am J Pathol. 2011;178:1792-804.

57. Nishii T, Yashiro M, Shinto O, Sawada T, Ohira M, Hirakawa K. Cancer stem cell-like SP cells have a high adhesion ability to the peritoneum in gastric carcinoma. Cancer Sci. 2009;100: 1397-402.

58. Gil J, Stembalska A, Pesz KA, Sasiadek MM. Cancer stem cells: the theory and perspectives in cancer therapy. J Appl Genet. 2008;49:193-9.

59. Kucia M, Reca R, Miekus K, Wanzeck J, Wojakowski W, Janowska-Wieczorek A, et al. Trafficking of normal stem cells and metastasis of cancer stem cells involve similar mechanisms: pivotal role of the SDF-1-CXCR4 axis. Stem Cells. 2005;23: 879-94.

60. Platet N, Liu SY, Atifi ME, Oliver L, Vallette FM, Berger F, et al. Influence of oxygen tension on CD133 phenotype in human glioma cell cultures. Cancer Lett. 2007;258:286-90.

61. Dean M, Fojo T, Bates S. Tumour stem cells and drug resistance. Nat Rev Cancer. 2005;5:275-84.

62. Keith B, Simon MC. Hypoxia-inducible factors, stem cells, and cancer. Cell. 2007;129:465-72.

63. Saini V, Shoemaker RH. Potential for therapeutic targeting of tumor stem cells. Cancer Sci. 2010;101:16-21.

64. Dylla SJ, Beviglia L, Park IK, Chartier C, Raval J, Ngan L, et al. Colorectal cancer stem cells are enriched in xenogeneic tumors following chemotherapy. PLoS One. 2008;3:e2428.

65. Johannessen TC, Bjerkvig R, Tysnes BB. DNA repair and cancer stem-like cells: potential partners in glioma drug resistance? Cancer Treat Rev. 2008;34:558-67.

66. Correia M, Machado JC, Ristimäki A. Basic aspects of gastric cancer. Helicobacter. 2009;14(s1):36-40.

67. Al-Hajj M. Cancer stem cells and oncology therapeutics. Curr Opin Oncol. 2007;19:61-4.

68. Massard C, Deutsch E, Soria JC. Tumour stem cell-targeted treatment: elimination or differentiation. Ann Oncol. 2006;17:1620-4.

69. Cruz FD, Matushansky I. Solid tumor differentiation therapyis it possible? Oncotarget. 2012;3:559-67.

70. Ohno R, Asou N, Ohnishi K. Treatment of acute promyelocytic leukemia: strategy toward further increase of cure rate. Leukemia. 2003;17:1454-63.

71. Ginestier C, Wicinski J, Cervera N, Monville F, Finetti P, Bertucci $F$, et al. Retinoid signaling regulates breast cancer stem cell differentiation. Cell Cycle. 2009;8:3297-302.

72. Piccirillo SG, Reynolds BA, Zanetti N, Lamorte G, Binda E, Broggi $G$, et al. Bone morphogenetic proteins inhibit the tumorigenic potential of human brain tumour-initiating cells. Nature (Lond). 2006;444:761-5.

73. Stojnev S, Pejcic M, Dolicanin Z, Velickovic LJ, Dimov I, Stefanovic V. Challenges of genomics and proteomics in nephrology. Ren Fail. 2009;31:765-72.

74. Peer D, Karp JM, Hong S, Farokhzad OC, Margalit R, Langer R. Nanocarriers as an emerging platform for cancer therapy. Nat Nanotechnol. 2007;2:751-60.

75. Shigdar S, Lin J, Yu Y, Pastuovic M, Wei M, Duan W. RNA aptamer against a cancer stem cell marker epithelial cell adhesion molecule. Cancer Sci. 2011;102:991-8.

76. Lambert JM. Drug-conjugated monoclonal antibodies for the treatment of cancer. Curr Opin Pharmacol. 2005;5:543-9.

77. Chari RV. Targeted cancer therapy: conferring specificity to cytotoxic drugs. ACC Chem Res. 2008;41:98-107.

78. Baldus SE, Mönig SP, Zirbes TK, Thakran J, Köthe D, Köppel $\mathrm{M}$, et al. Lewis (y) antigen (CD174) and apoptosis in gastric and colorectal carcinomas: correlations with clinical and prognostic parameters. Histol Histopathol. 2006;21:503-10. 
79. Boghaert ER, Sridharan L, Armellino DC, Khandke KM, DiJoseph JF, Kunz A, et al. Antibody-targeted chemotherapy with the calicheamicin conjugate hu3S193- $N$-acetyl gamma calicheamicin dimethyl hydrazide targets Lewis y and eliminates Lewis y-positive human carcinoma cells and xenografts. Clin Cancer Res. 2004;10:4538-49.

80. Scott AM, Tebbutt N, Lee FT, Cavicchiolo T, Liu Z, Gill S, et al. A phase I biodistribution and pharmacokinetic trial of humanized monoclonal antibody $\mathrm{Hu} 3 \mathrm{~s} 193$ in patients with advanced epithelial cancers that express the Lewis-Y antigen. Clin Cancer Res. 2007;13:3286-92.

81. Clavio M, Vignolo L, Albarello A, Varaldo R, Pierri I, Catania $\mathrm{G}$, et al. Adding low-dose gemtuzumab ozogamicin to fludarabine, Ara-C and idarubicin (MY-FLAI) may improve diseasefree and overall survival in elderly patients with non-M3 acute myeloid leukaemia: results of a prospective, pilot, multi-centre trial and comparison with a historical cohort of patients. Br J Haematol. 2007;138:186-95.

82. Katoh M. Networking of WNT, FGF, Notch, BMP, and Hedgehog signaling pathways during carcinogenesis. Stem Cell Rev. 2007;3:30-8.

83. Uemura N, Okamoto S, Yamamoto S, Matsumura N, Yamaguchi S, Yamakido M, et al. Helicobacter pylori infection and the development of gastric cancer. N Engl J Med. 2001;345:784-9.

84. Beachy PA, Karhadkar SS, Berman DM. Tissue repair and stem cell renewal in carcinogenesis. Nature (Lond). 2004;432: 324-31.

85. Kang DH, Han ME, Song MH, Lee YS, Kim EH, Kim HJ, et al. The role of hedgehog signaling during gastric regeneration. J Gastroenterol. 2009;44:372-9.

86. Malhotra GK, Zhao X, Band H, Band V. Shared signaling pathways in normal and breast cancer stem cells. J Carcinog. 2011;10:38.

87. Mutoh H, Hayakawa H, Sashikawa M, Sakamoto H, Sugano K. Direct repression of Sonic Hedgehog expression in the stomach by $\mathrm{Cdx} 2$ leads to intestinal transformation. Biochem $\mathrm{J}$. 2010;427:423-34.

88. Sherman AE, Zavros Y. Role of Sonic Hedgehog signaling during progression from inflammation to cancer in the stomach. World J Gastrointest Pathophysiol. 2011;2:103-8.

89. Zavros Y, Waghray M, Tessier A, Bai L, Todisco A, L Gumucio $\mathrm{D}$, et al. Reduced pepsin A processing of sonic hedgehog in parietal cells precedes gastric atrophy and transformation. J Biol Chem. 2007;282:33265-332.

90. Xiao C, Ogle SA, Schumacher MA, Orr-Asman MA, Miller ML, Lertkowit N, et al. Loss of parietal cell expression of Sonic hedgehog induces hypergastrinemia and hyperproliferation of surface mucous cells. Gastroenterology. 2010;138:550-61.

91. Berman DM, Karhadkar SS, Maitra A, Montes De Oca R, Gerstenblith MR, Briggs K, et al. Widespread requirement for Hedgehog ligand stimulation in growth of digestive tract tumours. Nature (Lond). 2003;425:846-51.

92. Lee KM, Lee JS, Jung HS, Park DK, Park HS, Hahm KB. Late reactivation of sonic hedgehog by Helicobacter pylori results in population of gastric epithelial cells that are resistant to apoptosis: implication for gastric carcinogenesis. Cancer Lett. 2010;287:44-53.

93. Li H, Fan X, Kovi RC, Jo Y, Moquin B, Konz R, et al. Spontaneous expression of embryonic factors and p53 point mutations in aged mesenchymal stem cells: a model of age related tumorigenesis in mice. Cancer Res. 2007;67:10889-98.

94. Martin J, Donnelly JM, Houghton J, Zavros Y. The role of sonic hedgehog reemergence during gastric cancer. Dig Dis Sci. 2010;55:1516-24.

95. Xu X, Zhang X, Wang S, Qian H, Zhu W, Cao H, et al. Isolation and comparison of mesenchymal stem-like cells from human gastric cancer and adjacent non-cancerous tissues. J Cancer Res Clin Oncol. 2011;137:495-504.

96. Fukaya M, Isohata N, Ohta H, Aoyagi K, Ochiya T, Saeki N, et al. Hedgehog signal activation in gastric pit cell and in diffuse type gastric cancer. Gastroenterology. 2006;131:14-29.

97. Song Z, Yue W, Wei B, Wang N, Li T, Guan L, et al. Sonic hedgehog pathway is essential for maintenance of cancer stemlike cells in human gastric cancer. PLoS One. 2011;6:e17687.

98. Gupta S, Takebe N, Lorusso P. Targeting the Hedgehog pathway in cancer. Ther Adv Med Oncol. 2010;2:237-50.

99. Scales SJ, de Sauvage FJ. Mechanisms of Hedgehog pathway activation in cancer and implications for therapy. Trends Pharmacol Sci. 2009;30:303-12.

100. Stanton BZ, Peng LF, Maloof N, Nakai K, Wang X, Duffner JL, et al. A small molecule that binds Hedgehog and blocks its signaling in human cells. Nat Chem Biol. 2009;5:154-6.

101. Lauth M, Bergstrom A, Shimokawa T, Toftgard R. Inhibition of GLI-mediated transcription and tumor cell growth by small molecule antagonists. Proc Natl Acad Sci USA. 2007;104: 8455-60.

102. Katoh M, Katoh M. Notch signaling in gastrointestinal tract. Int J Oncol. 2007;30:247-51.

103. Androutsellis-Theotokis A, Leker RR, Soldner F, Hoeppner DJ, Ravin R, Poser SW, et al. Notch signaling regulates stem cell numbers in vitro and in vivo. Nature (Lond). 2006;442:823-6.

104. Dang TP, Gazdar AF, Virmani AK, Sepetavec T, Hande KR, Minna JD, et al. Chromosome 19 translocation, overexpression of Notch3, and human lung cancer. J Natl Cancer Inst. 2000;92:1355-7.

105. Reedijk M, Odorcic S, Chang L, Zhang H, Miller N, McCready DR, et al. High-level coexpression of JAG1 and NOTCH1 is observed in human breast cancer and is associated with poor overall survival. Cancer Res. 2005;65:8530-7.

106. Park JT, Li M, Nakayama K, Mao TL, Davidson B, Zhang Z, et al. Notch3 gene amplification in ovarian cancer. Cancer Res. 2006;66:6312-8.

107. Sekine A, Akiyama Y, Yanagihara K, Yuasa Y. Hath1 up-regulates gastric mucin gene expression in gastric cells. Biochem Biophys Res Commun. 2006;344:1166-71.

108. Piazzi G, Fini L, Selgrad M, Garcia M, Daoud Y, Wex T, et al. Epigenetic regulation of Delta-Like1 controls Notch1 activation in gastric cancer. Oncotarget. 2011;2:1291-301.

109. Sun Y, Gao X, Liu J, Kong QY, Wang XW, Chen XY, et al. Differential Notch1 and Notch2 expression and frequent activation of Notch signaling in gastric cancers. Arch Pathol Lab Med. 2011;135:451-8.

110. Sarmento LM, Barata JT. Therapeutic potential of Notch inhibition in T-cell acute lymphoblastic leukemia: rationale, caveats and promises. Expert Rev Anticancer Ther. 2011;11:1403-15.

111. Real PJ, Ferrando AA. NOTCH inhibition and glucocorticoid therapy in T-cell acute lymphoblastic leukemia. Leukemia. 2009;23:1374-7.

112. Grosveld GC. Gamma-secretase inhibitors: Notch so bad. Nat Med. 2009;15:20-1.

113. Yilmaz OH, Valdez R, Theisen BK, Guo W, Ferguson DO, Wu $\mathrm{H}$, et al. PTEN dependence distinguishes haematopoietic stem cells from leukaemia-initiating cells. Nature (Lond). 2006;441:475-82.

114. Fan X, Matsui W, Khaki L, Stearns D, Chun J, Li YM, et al. Notch pathway inhibition depletes stem-like cells and blocks engraftment in embryonal brain tumors. Cancer Res. 2006;66: 7445-52.

115. Lu D, Choi MY, Yu J, Castro JE, Kipps TJ, Carson DA. Salinomycin inhibits Wnt signaling and selectively induces apoptosis in chronic lymphocytic leukemia cells. Proc Natl Acad Sci USA. 2011;108:13253-7. 
116. Clements WM, Wang J, Sarnaik A, Kim OJ, MacDonald J, Fenoglio-Preiser $\mathrm{C}$, et al. Catenin mutation is a frequent cause of Wnt pathway activation in gastric cancer. Cancer Res. 2002;62:3503-6.

117. Katoh M, Katoh M. WNT signaling pathway and stem cell signaling network. Clin Cancer Res. 2007;13:4042-5.

118. Katoh M, Katoh M. Cross-talk of WNT and FGF signaling pathways at GSK3h to regulate h-catenin and SNAIL signaling cascade. Cancer Biol Ther. 2006;5:1059-64.

119. Cai C, Zhu X. The Wnt/ $\beta$-catenin pathway regulates selfrenewal of cancer stem-like cells in human gastric cancer. Mol Med Rep. 2012;5:1191-6.

120. Gupta PB, Onder TT, Jiang G, Tao K, Kuperwasser C, Weinberg $\mathrm{RA}$, et al. Identification of selective inhibitors of cancer stem cells by high-throughput screening. Cell. 2009;138:645-59.

121. Zhi QM, Chen XH, Ji J, Zhang JN, Li JF, Cai Q, et al. Salinomycin can effectively kill ALDH(high) stem-like cells on gastric cancer. Biomed Pharmacother. 2011;65:509-15.

122. Palm W, de Lange T. How shelterin protects mammalian telomeres. Annu Rev Genet. 2008;42:301-34.

123. Harley CB. Telomerase and cancer therapeutics. Nat Rev Cancer. 2008;8:167-79.

124. Shay JW, Keith WN. Targeting telomerase for cancer therapeutics. Br J Cancer. 2008;98:677-83.

125. Zhang H, Yang MH, Zhao JJ, Chen L, Yu ST, Tang XD, et al. Inhibition of tankyrase 1 in human gastric cancer cells enhances telomere shortening by telomerase inhibitors. Oncol Rep. 2010;24:1059-65.

126. Han MH, Kim GY, Moon SK, Kim WJ, Nam TJ, Choi YH. Apoptosis induction by glycoprotein isolated from Laminaria japonica is associated with down-regulation of telomerase activity and prostaglandin E2 synthesis in AGS human gastric cancer cells. Int J Oncol. 2011;38:577-84.

127. Yao XX, Yin L, Sun ZC. The expression of hTERT mRNA and cellular immunity in gastric cancer and precancerosis. World $\mathrm{J}$ Gastroenterol. 2002;8:586-90.

128. Lou H, Dean M. Targeted therapy for cancer stem cells: the patched pathway and ABC transporters. Oncogene. 2007;26: 1357-60.

129. Frank NY, Margaryan A, Huang Y, Schatton T, Waaga-Gasser AM, Gasser M, et al. ABCB5-mediated doxorubicin transport and chemoresistance in human malignant melanoma. Cancer Res. 2005;65:4320-33.
130. Peng H, Qi J, Dong Z, Zhang JT. Dynamic vs. static ABCG2 inhibitors to sensitize drug resistant cancer cells. PLoS One. 2010;5:e15276.

131. Mills JC, Shivdasani RA. Gastric epithelial stem cells. Gastroenterology. 2011;140:412-24.

132. Bissell MJ, Labarge MA. Context, tissue plasticity, and cancer: are tumor stem cells also regulated by the microenvironment? Cancer Cell. 2005;7:17-23.

133. Polyak K, Hahn WC. Roots and stems: stem cells in cancer. Nat Med. 2006;12:296-300.

134. Yang ZJ, Wechsler-Reya RJ. Hit 'em where they live: targeting the cancer stem cell niche. Cancer Cell. 2007;11:3-5.

135. Hombach-Klonisch S, Paranjothy T, Wiechec E, Pocar P, Mustafa T, Seifert A, et al. Cancer stem cells as targets for cancer therapy: selected cancers as examples. Arch Immunol Ther Exp. 2008;56:165-80.

136. Cao H, Xu W, Qian H, Zhu W, Yan Y, Zhou H, et al. Mesenchymal stem cell-like cells derived from human gastric cancer tissues. Cancer Lett. 2009;274:61-71.

137. Mishra PJ, Mishra PJ, Humeniuk R, Medina DJ, Alexe G, Mesirov JP, et al. Carcinoma-associated fibroblast-like differentiation of human mesenchymal stem cells. Cancer Res. 2008;68:4331-9.

138. Guo X, Oshima H, Kitmura T, Taketo MM, Oshima M. Stromal fibroblasts activated by tumor cells promote angiogenesis in mouse gastric cancer. J Biol Chem. 2008;283:19864-71.

139. Hummel R, Hussey DJ, Haier J. MicroRNAs: predictors and modifiers of chemo- and radiotherapy in different tumour types. Eur J Cancer. 2010;46:298-311.

140. Ma YY, Tao HQ. Microribonucleic acids and gastric cancer. Cancer Sci. 2012;103:620-5.

141. Olmeda D, Jorda M, Peinado H, Fabra A, Cano A. Snail silencing effectively suppresses tumour growth and invasiveness. Oncogene. 2010;26:1862-74.

142. Kim SU, Jeung EB, Kim YB, Cho MH, Choi KC. Potential tumor-tropic effect of genetically engineered stem cells expressing suicide enzymes to selectively target invasive cancer in animal models. Anticancer Res. 2011;31:1249-58.

143. Kim KY, Yi BR, Lee HR, Kang NH, Jeung EB, Kim SU, et al. Stem cells with fused gene expression of cytosine deaminase and interferon- $\beta$ migrate to human gastric cancer cells and result in synergistic growth inhibition for potential therapeutic use. Int J Oncol. 2012;40:1097-104. 